\section{Retinal function in infants with optic nerve hypoplasia: electroretinograms to large patterns and photopic flash}

${ }^{1}$ Department of Vision Sciences, Glasgow Caledonian University, Glasgow, Lanarkshire, UK

${ }^{2}$ Division of Ophthalmology, Childrens Hospital LA, Los Angeles, CA, USA

${ }^{3}$ Department of Ophthalmology, Keck School of Medicine, University of Southern California, Los Angeles, CA, USA

Correspondence: DL McCulloch, Department of Vision Sciences,

Glasgow Caledonian University, Cowcaddens Road Glasgow, Lanarkshire, G4 OBA, UK

Tel: +441413313379;

Fax: + 441413313387

E-mail:dlmc@

gcal.ac.uk

Received: 10 February 2005 Accepted in revised form: 3 January 2006 Published online: 7 April 2006

Some of the material in this paper was presented to the Association for Research in Vision and Ophthalmology (ARVO), April 2002

\section{Abstract}

Aims Optic nerve hypoplasia (ONH), which is defined as a congenital deficiency of retinal ganglion cells, may also involve more distal layers of the retina. We investigated electrophysiological function of the retina in ONH using electroretinograms (ERGs).

Methods ERGs were recorded from 48 subjects (3.5-35 months) with unilateral or bilateral ONH. Pattern reversal ( $4^{\circ}$ checks) was presented under chloral hydrate sedation, using an optical system to correct a cycloplegic refraction. A photopic flash stimulus was also used. Fundus photographs were used to measure the disk diameter/disk macula ratio (DD/DM), and to document other clinical signs. Eyes were classified as moderate $(0.15-0.3)$ or severe $(<0.15) \mathrm{ONH}$, and those with $\mathrm{DD} / \mathrm{DM}$ greater than 0.3 were used as reference eyes.

Results Pattern ERG recording was completed in 89 eyes and was detectable in $80 \%$ of eyes with ONH (61/76 tested) and in all 13 reference eyes. Photopic flash ERGs were of good quality in all eyes. The severity of $\mathrm{ONH}$ correlates with the amplitude of the photopic flash b-waves and with the amplitude of the N95 component of the pattern ERG $(P<0.01)$. However, the ERGs to large patterns were well preserved $(>3.5 \mu \mathrm{V})$ in 10 of 35 eyes with severe $\mathrm{ONH}$. Tortuous retinal vessels in eyes with either moderate or severe $\mathrm{ONH}$ were associated with smaller amplitude photopic b-waves and markedly diminished or undetectable pattern ERGs.

Conclusions This study supports the hypothesis that retinal dysfunction distal to the ganglion cells is common in $\mathrm{ONH}$, but is not predictable on the basis of ONH severity alone. Additionally, tortuous retinal vessels in
DL McCulloch¹, P Garcia-Fillion², GB van Boemel $^{3}$ and MS Borchert ${ }^{2}$

ONH may be a sign associated with retinal dysfunction.

Eye (2007) 21, 712-720; doi:10.1038/sj.eye.6702309; published online 7 April 2006

Keywords: optic nerve hypoplasia (ONH); neuro-ophthalmology; electroretinogram (ERG); pattern ERG (PERG); paediatric ophthalmology

\section{Introduction}

Optic nerve hypoplasia (ONH), congenital dysgenesis of the optic nerves, is an important cause of visual dysfunction in childhood. By definition, $\mathrm{ONH}$ is a congenital deficiency of retinal ganglion cells and their axons that form the optic nerve. Few histological descriptions of $\mathrm{ONH}$ exist, and even fewer with clinicopathological correlation. In general, the only retinal abnormality is deficiency of the retinal ganglion cells and nerve fibre layer. ${ }^{1}$ $\mathrm{ONH}$ may occur as an isolated unilateral or bilateral condition but it is also frequently associated with other congenital anomalies, often as part of the triad of septo-optic dysplasia, De Moisiers Syndrome (ONH with pituitary hormone deficiencies and midline brain lesions). ${ }^{2-6}$ Although a number of risk factors have been identified, the pathogenesis of $\mathrm{ONH}$ remains unclear and is likely multifactorial.

Visual function in $\mathrm{ONH}$ varies with the severity of the condition from nearly normal to no light perception. ${ }^{5-7}$ Along the severity continuum, there are some cases with sectoral defects in the optic nerve head, and there is a frequent coincidence of $\mathrm{ONH}$ and pallor of these small optic nerve heads. ${ }^{8}$ Prognosis for vision can be difficult to establish based on clinical observation. Both neuro-radiological 
studies and anthropomorphic measurements aid in establishing the diagnosis and prognosis for young infants with $\mathrm{ONH}^{9-18}$ Visual evoked potential (VEP) testing can give a functional measure of vision early in life. In ONH, the amplitude of VEPs to flash stimulation and the presence of VEPs to pattern stimulation are correlated with visual function. ${ }^{7,14,17-19}$

Typically, $\mathrm{ONH}$ is characterized by normal full-field electroretinograms (ERGs) and abnormal VEPs. ${ }^{16-19}$ The a-waves of flash ERGs are consistently reported as normal in $\mathrm{ONH}$, but several authors have reported abnormalities in the b-wave. ${ }^{20,21}$ Under photopic conditions, the b-wave is generated by the postreceptoral ON and OFF pathways mediated by the depolarizing and hyperpolarizing bipolar cells of the retina, with no significant contribution from ganglion cells. ${ }^{22-24}$ Thus, abnormalities in the photopic b-wave are evidence for dysfunction distal to the ganglion cells.

The generators of the pattern ERG are proximal to those of the flash ERG, with a major contribution from spiking cells of the inner retina. Pharmacological blockade of the ganglion cells and spiking amacrine cells with TTX in primates eliminates the negative component of the pattern ERG (N95). ${ }^{23}$ Generators of the positive component of the pattern ERG (P50) have not been as well localized. They are clearly distinct from those of the N95, as the effect of TTX on P50 is spatially tuned; P50 is largely preserved with large pattern stimuli but it is diminished with a shortened implicit time for small patterns. In clinical disorders causing optic atrophy, and in severe experimentally induced glaucoma in primates, both the P50 and N95 are affected, suggesting that damage is not limited to the spiking neurons of the inner retina. ${ }^{25-28}$ Thus, generation of the N95 requires functional spiking cells. P50 for small patterns involves both spiking cells and more distal generators, whereas for large patterns, it may rely entirely on more distal generators, similar to those of focal ERGs that reflect local luminance. ${ }^{23,27}$

Pattern electroretinography requires good fixation and a clear retinal image. To date, pattern ERGs in ONH have not been reported. In the ongoing CHLA prospective study of prenatal and clinical risk factors of $\mathrm{ONH}$, an examination with chloral hydrate sedation and electrodiagnostic testing are part of the protocol. Fortuitously, nystagmus is suppressed during sedation. We have devised a strategy for recording pattern ERGs in young children with ONH. In the present series, we report flash ERGs and large pattern ERGs to evaluate and distinguish between the function of the inner retinal spiking cells and the more distal retinal layers in $\mathrm{ONH}$.

\section{Materials and methods}

\section{Subjects}

A sequential series of 48 subjects ( 20 girls and 28 boys) recruited to the CHLA prospective study of prenatal and clinical risk factors of $\mathrm{ONH}$ are reported here. Inclusion criteria are referral before 3 years of age and a small optic nerve in at least one eye defined by a ratio of less than 0.3 between the disk diameter (DD) and the disk macula (DM) distance (DD/DM). ${ }^{7}$ Parents gave fully informed consent to participate in the study, which was approved by the hospital ethical committee and conforms to the declaration of Helsinki. A comprehensive protocol of ophthalmology, neuro-radiography, endocrine, and psychometric assessments is carried out annually until 5 years of age. The present report includes electroretinography and ocular biometry collected under sedation at the initial study visit. Normative data collection with a protocol requiring sedation is unethical. Comparisons are made across the range of severity of $\mathrm{ONH}$, including the unaffected eyes of unilateral cases as reference eyes.

The subjects ranged in age from 16 weeks to 37 months of age at the time of ERG testing (median age 14.4 months). Neuro-radiography, including MRI scan data, is available for 31 subjects. Twenty of these subjects (65\%) have structural abnormalities in addition to $\mathrm{ONH}$ (nine with hypoplasia of the corpus callosum; 11 with absence of the septum pellucidum (including five with both) and five children with other neurological defects). Follow-up data for endocrine function are available for 37 subjects. Nineteen of these children $(51 \%)$ have hypopituitarism.

\section{Ocular biometry and clinical signs}

An experienced paediatric ophthalmologist (MSB) analysed fundus photographs while masked to the identity and clinical status of the subjects. The diameter of the neural tissue of the optic disk (DD) and the distance between the temporal margin of the disk and the centre of the macula (DM) were measured directly from printed photographs (Figure 1). DD/DM ratios of 0.3 or greater are associated with normal vision and were classed as reference eyes; those between 0.3 and 0.15 were classed as moderate $\mathrm{ONH}$; and a DD/DM of 0.15 or less was severe ONH. ${ }^{6}$ The observer also judged the retinal vessels for tortuosity (ranked within normal limits, tortuous veins only or tortuous veins and arteries) and assessed the presence or absence of double ring sign. Optic nerve colour was classified as normal, temporal pallor, or overall pallor.

\section{ERG methods}

Subjects had full mydriasis and cycloplegia with three drops in each eye of a combined solution 


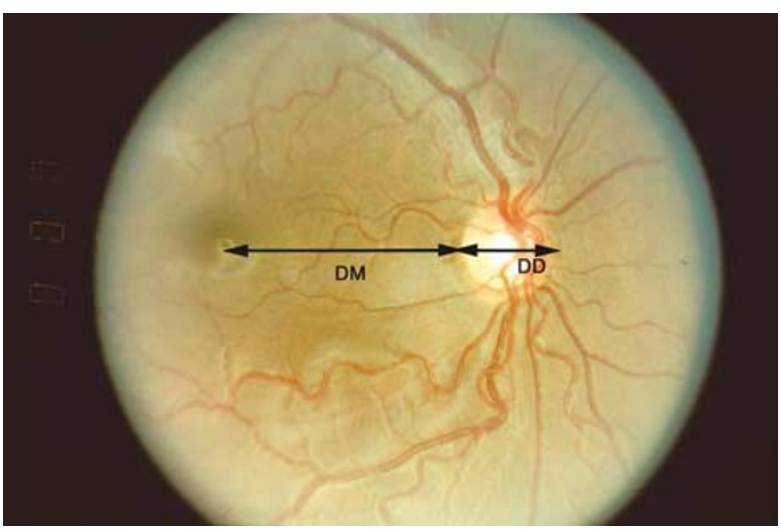

Figure 1 Optic nerve hypoplasia was quantified using the disk diameter (DD) to disk macula (DM) ratio as shown above for a fellow eye with a DD/DM of 0.35 .

( $1 \%$ cyclopentolate and $2.5 \%$ phenylepharine). Following this, they were sedated with chloral hydrate $(100 \mathrm{mg} / \mathrm{kg}$, orally or by rectal suppository) for electroretinography, fundus examination, and fundus photography. A nurse monitored vital signs until recovery. In all subjects, nystagmus was completely suppressed during sedation.

Conjunctival electrodes (DTL fibre or HK loop electrodes) were inserted and referenced to a silver-silver chloride skin electrode near the ipsilateral outer canthus (Figure 2). ${ }^{29,30}$ These two electrode types give very similar pattern ERG data. ${ }^{31}$ An indifferent electrode was attached to the earlobe or mastoid. Flash ERGs were amplified 5000 times and pattern ERGs were amplified 20000 times. The amplifier bandwidth was $1-100 \mathrm{~Hz}$.

\section{Flash stimulation}

ERGs were recorded monocularly with a light-excluding black patch covering the opposite eye. The eyelid was held open and non-standard brief flash $\left(1.3 \mathrm{~cd} \mathrm{~s} / \mathrm{m}^{2}\right)$ was delivered to the posterior pole at $2.03 \mathrm{~Hz}$ from a large screen monitor $(25 \times 32$ degrees). Standard full-field ERG stimuli were not available when this cohort was tested. Data from 100 flashes were stored for off-line processing.

\section{Pattern stimulation}

Clear optical images for pattern testing were obtained using a correcting optical system. First, the cycloplegic refraction was measured by retinoscopy. A correction incorporating an additional +1.5 dioptres to compensate for the distance to the stimulus was placed before the eye. The subject, in supine position, was then placed under a front surface mirror and the corneal reflection of the stimulus was centred in the pupil. The eye was opened manually, interrupted with blinks to maintain corneal hydration. Fixation was monitored throughout testing, and recording was paused whenever
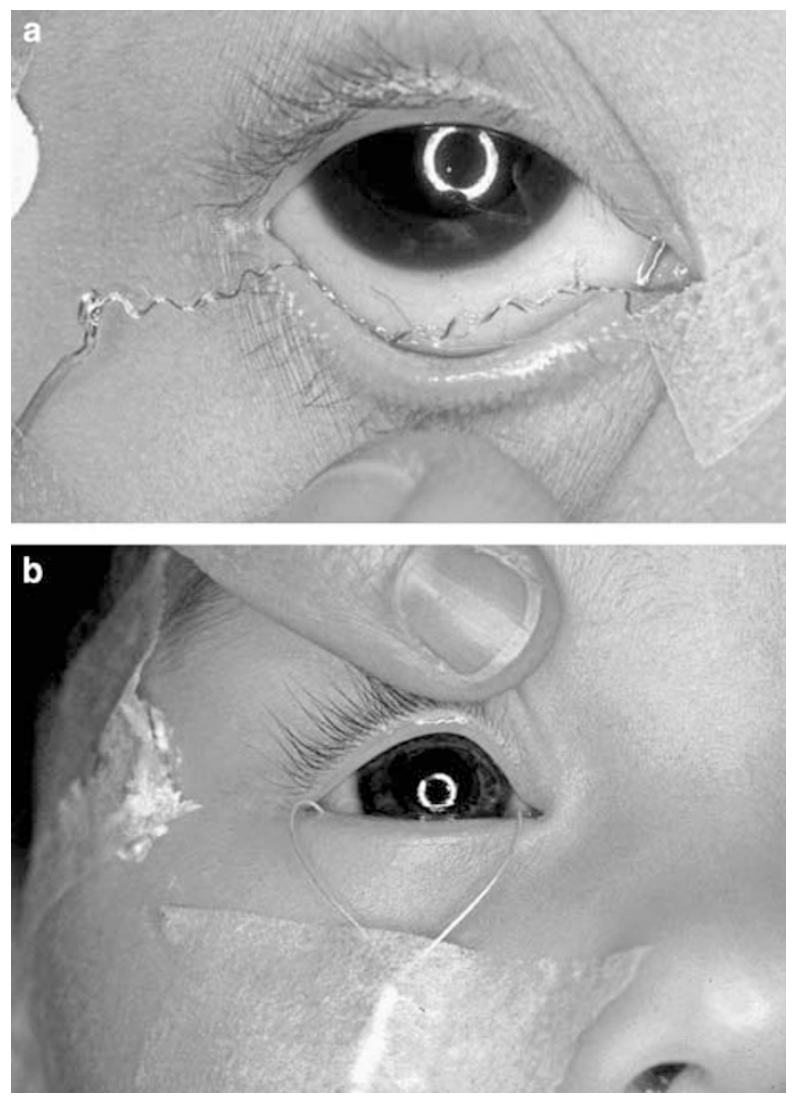

Figure 2 (a, b) Placement of the DTL fibre (upper) and HK loop (lower) electrodes in the lower conjunctival sac is shown. For both electrode types, the reference electrode was placed near the ipsilateral outer canthus.

adjustments to the position of the head and/or mirror were required to maintain centration in the pupil.

The stimulus was a high contrast (95\%) checkerboard array of 48 checks $(8 \times 6)$ reversing 2.03 times per second on a large high-resolution screen $(32 \times 24$ degrees), positioned $67 \mathrm{~cm}$ from the eye. The checks subtended $4^{\circ}$ of visual angle, so four check widths would be positioned between the fovea and the optic disk. Raw data for 320 pattern reversals were digitized and stored for off-line processing on a Neuroscan evoked potential system (Neuroscientific, Herondon, PA, USA).

\section{Signal processing}

For each subject, the raw data for each electrode consisted of 320 epochs of $200 \mathrm{~ms}$, following each pattern reversal. Noise, blink artifacts, and shifts in the baseline associated with eye movements were retained in the raw data. The signals were then digitally filtered with a band pass of 1-50 Hz. Next, each epoch was adjusted off line to a zero mean baseline (baseline correction routine, Neurosoft Inc.), and then the mean slope by linear regression was also adjusted to zero (linear detrend, 
Neurosoft Inc.). Following this processing, epochs still containing artefacts greater than $\pm 80 \mu \mathrm{V}$ were rejected. Two separate averaged pattern ERGs were then produced using half of the retained epochs for each average so that reproducibility could be evaluated. The intraclass correlation statistic (Neurosoft Inc.) was used to objectively measure the related variability of the two pattern ERG averages. This statistic ranges from 0 for dissimilar signals to 1 for identical signals. The authors also rated quality subjectively as excellent, good, fair, or poor by observation of the superimposed averages, while masked to the clinical status of the subject. Amplitudes and peak times for the P50 and N95 were recorded from the grand average.

\section{Results}

\section{Subjects}

Twelve cases were classified as unilateral $\mathrm{ONH}$, as the $\mathrm{DD} / \mathrm{DM}$ was greater than 0.3 in the better eye. Of the 36 bilateral cases, 32 were symmetrical $(89 \%)$ with less than a $30 \%$ difference between DD/DM of the right and left eyes. Spontaneous nystagmus was present in $90 \%$ of the bilateral cases, and $45 \%$ of the cases were classified as unilateral.

Eyes were classified as follows: 13 reference eyes (DD/ $\mathrm{DM}>0.3$ including one borderline case with $\mathrm{DD} / \mathrm{DM}$ of 0.31 and 0.34 for the right and left eyes, respectively), 46 eyes with moderate $\mathrm{ONH}(0.15<\mathrm{DD} / \mathrm{DM}<0.30)$, 35 eyes with severe $\mathrm{ONH}(\mathrm{DD} / \mathrm{DM} \leq 0.15)$, and one severely microphthalmic eye that was excluded from the quantitative analysis. Tortuous retinal veins were apparent in 34 eyes with $\mathrm{ONH}(41.4 \%)$ and in none of the reference eyes. Tortuosity of arteries and veins was observed in 18 eyes (Table 1). Tortuous retinal vessels (ranked none, veins only, or all vessels) are more prevalent in those with more severe ONH (Kendall's rank correlation, $\tau=0.33, P=0.001)$. Endocrine dysfunction is also more prevalent in subjects with tortuous retinal vessels $\left(\chi^{2}=4.7, P=0.03\right)$. Of the 37 subjects with known endocrine outcomes, 13/20 (71\%) of those treated or monitored for hypopituatrism have tortuous vessels in at least one eye, whereas only 5/17 (28\%) with normal vascular appearance in both eyes have clinically significant endocrine dysfunction.

Pallor of the temporal optic nerve head was evident in 32 eyes, including one fellow eye of a unilateral case. An additional 20 eyes with ONH showed pallor of the entire disk, demonstrating the frequent concurrence of optic atrophy and $\mathrm{ONH}^{8}$ (Table 1). The prevalence and extent of optic nerve pallor increased with the severity of $\mathrm{ONH}$ $(\tau=0.24, P<0.001)$. Double ring sign was evident in 78 eyes $(82 \%)$ including five of the 13 eyes classified as reference eyes (Table 1). The association between double ring sign and the severity of $\mathrm{ONH}$ is also significant ( $\tau=0.33, P<0.001$ ).

There were no differences in the severity of $\mathrm{ONH}$ or the presence of the above clinical signs based on the age of the subjects. All eyes had a clinically normal maculae except one eye with severe $\mathrm{ONH}$ and mild foveal hypoplasia. The same eye had irregular disk margins, and an additional eye with moderate $\mathrm{ONH}$ had mylention in the nerve fibre layer. The DD/DM ratio was estimated in these two cases.

\section{Flash ERGs}

Non-standard photopic flash ERGs with clearly reproduced a- and b-waves were recorded in all eyes, except the microphthalmic eye that was not tested (Figure 3). The a-wave showed no association with the severity of $\mathrm{ONH}$. However, b-wave amplitude was significantly smaller in eyes with more severe $\mathrm{ONH}$ based on the DD/DM ratio $\left(r^{2}=0.08, P<0.01\right)$. Figure 4 demonstrates this association with the group mean amplitudes, although the association is not apparent in individual examples, as the b-wave is variable with considerable overlap between $\mathrm{ONH}$ groups. The ratio of the b-wave/a-wave amplitudes also varies with the severity of $\mathrm{ONH}$ : mean a:b ratios were 2.0, 1.8, and 1.6 for eyes classified as fellow, moderate, and severe $\mathrm{ONH}$, respectively $(\tau=0.14, P=0.01)$. Neither the photopic b-wave amplitude nor the a:b ratio was significantly associated with the presence of vessel tortuosity, endocrine dysfunction, or neuro-radiographical abnormalities, or with the age of the subject. There were no eyes with severely diminished $b$-waves (negative ERGs) or with very large b-waves using this single stimulus.

\section{Large pattern ERGs}

Pattern ERGs were completed and technically acceptable in 89/96 eyes. The eyes excluded were one

microphthalmic eye, four eyes not tested when a child awoke from sedation (two eyes in one case of moderate bilateral $\mathrm{ONH}$, one eye from a severe bilateral case, and one eye from a moderate bilateral case), and two further eyes with high noise levels (one eye from two separate cases of moderate bilateral $\mathrm{ONH}$ ). Mean values for the intraclass statistic (indicating the reproducibility) were $0.71,0.51$, and 0.44 for pattern ERGs rated as good, fair, and undetectable, respectively. This intraclass measure of reproducibility shows a strong association with the subjective quality rating (ANOVA, $P<0.001$ ). Although this statistic could be useful to quantify reproduction of the pattern ERGs, we found the subjective rating more 
Table 1 Severity of $\mathrm{ONH}^{\mathrm{a}}$ with associated ocular signs and ERG data

\begin{tabular}{|c|c|c|c|}
\hline & $\begin{array}{c}\text { Severe ONH } D D / D M<0.15 \\
\text { (no. of eyes }=36)\end{array}$ & $\begin{array}{c}\text { Moderate } O N H D D / D M<0.3 \\
\quad(\text { no. of eyes }=46)\end{array}$ & $\begin{array}{c}\text { Fellow eyes } D D / D M>0.3 \\
\quad \text { (no. of eyes }=13)\end{array}$ \\
\hline \multicolumn{4}{|l|}{ Double ring sign ${ }^{\mathrm{b}}$} \\
\hline Yes & $33(92 \%)$ & $40(87 \%)$ & $5(38 \%)$ \\
\hline No & $3(8 \%)$ & $6(13 \%)$ & $8(62 \%)$ \\
\hline \multicolumn{4}{|l|}{ Tortuous vessels ${ }^{\mathrm{b}}$} \\
\hline Veins and arteries & $9(25 \%)$ & $7(15 \%)$ & Nil \\
\hline Veins only & $10(28 \%)$ & $8(17 \%)$ & Nil \\
\hline Unremarkable & $17(47 \%)$ & $31(67 \%)$ & $13(100 \%)$ \\
\hline \multicolumn{4}{|l|}{ Pallor $^{\mathrm{b}}$} \\
\hline General & $13(36 \%)$ & $7(15 \%)$ & Nil \\
\hline Temporal & $8(22 \%)$ & $23(50 \%)$ & $1(8 \%)$ \\
\hline No pallor & $15(42 \%)$ & $16(35 \%)$ & $12(92 \%)$ \\
\hline \multicolumn{4}{|l|}{ ERG implicit times } \\
\hline \multicolumn{4}{|l|}{ Flash } \\
\hline A-wave & $16.2( \pm 3) \mathrm{ms}$ & $16.3( \pm 3) \mathrm{ms}$ & $16.7( \pm 3) \mathrm{ms}$ \\
\hline B-wave & $37.7( \pm 5) \mathrm{ms}$ & $37.5( \pm 6) \mathrm{ms}$ & $38.5( \pm 3) \mathrm{ms}$ \\
\hline \multicolumn{4}{|l|}{ Large check ERGs ${ }^{c}$} \\
\hline P50 (ms) & $47.3( \pm 6) \mathrm{ms}$ & $50.4( \pm 8) \mathrm{ms}$ & $50.1( \pm 9) \mathrm{ms}$ \\
\hline N95 (ms) & $82.8( \pm 16) \mathrm{ms}$ & $90.8( \pm 16) \mathrm{ms}$ & $93.3( \pm 18) \mathrm{ms}$ \\
\hline \multicolumn{4}{|l|}{ ERG amplitudes } \\
\hline \multicolumn{4}{|l|}{ Flash } \\
\hline A-wave & $-61( \pm 28) \mu \mathrm{V}$ & $-59( \pm 23) \mu \mathrm{V}$ & $-68( \pm 31) \mu \mathrm{V}$ \\
\hline B-wave ${ }^{b}$ & $99( \pm 46) \mu \mathrm{V}$ & $102( \pm 48) \mu \mathrm{V}$ & $131( \pm 64) \mu \mathrm{V}$ \\
\hline \multicolumn{4}{|l|}{ Large check $E R G s^{\mathrm{d}}$} \\
\hline Detectable $^{\mathrm{b}}$ & $21 / 35(60 \%)$ & $31 / 41(76 \%)$ & $13 / 13(100 \%)$ \\
\hline P50, median (range) & $1.6 \mu \mathrm{V}(0-6.1)$ & $2.2 \mu \mathrm{V}(0-9.9)$ & $3.5 \mu \mathrm{V}(1.2-4.7)$ \\
\hline N95, median (range) ${ }^{\mathrm{b}}$ & $2.8 \mu \mathrm{V}(0-8.3)$ & $2.9 \mu \mathrm{V}(0-11.2)$ & $3.6 \mu \mathrm{V}(1.1-10.2)$ \\
\hline $\mathrm{P} 50 / \mathrm{N} 95$ ratio & $0.93( \pm 0.5)$ & $1.2( \pm 1.2)$ & $1.3( \pm 1.6)$ \\
\hline
\end{tabular}

$\mathrm{DD} / \mathrm{DM}$, disk diameter/disk macula; ERGs, electroretinograms; ONH, optic nerve hypoplasia.

${ }^{\mathrm{a} O n e}$ eye with microphthalmos is excluded.

bIndicates significant associations with severity based on DD/DM ratio.

Implicit times from stimulus to peak are given for the mean \pm SD for detectable ERGs.

${ }^{\mathrm{d} A}$ Amplitude median and range for all subjects. One severe eye and five moderate eyes are excluded on technical grounds (see Results).

reliable, as the intraclass value can be artificially high or low when artefact or noise is present in one or both of the pattern ERG averages.

Overall, 65 of the 89 eyes tested had clearly detectable and reproducable pattern ERGs (rated good or fair quality). Thirty-one eyes had P50 to N95 amplitudes greater than $3.5 \mu \mathrm{V}$, 34 eyes had clearly detectable pattern ERGs of smaller amplitude, and 24 eyes had undetectable pattern ERGs (Figure 5). All 13 reference eyes had detectable pattern ERGs to large checks (Table 1). In eyes with ONH, pattern ERGs were detectable in 76 and $60 \%$ of eyes with moderate and severe $\mathrm{ONH}$, respectively. Thus, undetectable pattern ERGs were more prevalent in eyes with more severe $\mathrm{ONH}(\tau=-0.24, P<0.001$ for PERG detected vs DD/DM). The amplitude from P50 to
N95 was significantly correlated with the DD/DM ratio (Spearman's $\rho=0.26, P<0.02$ ) (Figure 6). The trends for P50 amplitude and for the implicit times of both components did not reach significance. Within each ONH severity category, all aspects of these pattern ERGs were invariant with age.

In this population of children with $\mathrm{ONH}$, the prevalence of small or absent pattern ERGs in either eye did not differ between those with and without endocrine dysfunction, or between those with and without other neurological dysfunction ( $t$-tests $P>0.4$ ). Vascular tortuosity was, however, strongly associated with small or absent pattern ERGs $(\tau=0.25, P<0.001$ for tortuosity ranked all vessels, veins only, or none vs P50-N95 amplitude). Only one of 15 eyes with tortuosity of both 

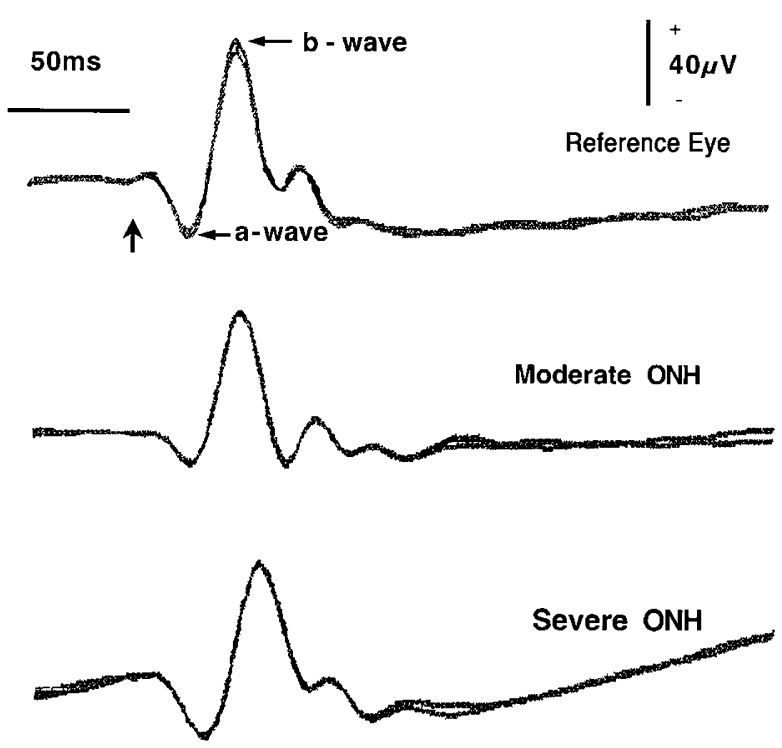

Figure 3 Typical flash ERGs for the non-standard $1.3 \mathrm{~cd} \mathrm{~s} / \mathrm{m}^{2}$ stimulus are shown for eyes with severe and moderate $\mathrm{ONH}$ and for a fellow eye. All ERGs demonstrate clear a- and b-waves. Arrow indicates flash time.

veins and arteries had a large-amplitude pattern ERG $(>3.5 \mu \mathrm{V})$, whereas large amplitudes were recordable in $44 \%$ of eyes with clinically normal vessels (Table 2 ).

\section{Discussion}

The present series of 48 infants show the expected spectrum of $\mathrm{ONH}$ severity and of associated conditions, including endocrine dysfunction and neural malformations. ${ }^{4,5,32-34}$ Although reports of ERGs in ONH are few, they agree that flash ERGs are normal in the majority of cases. ${ }^{17-21,34,35}$ However, normal ERGs are not universal and a variety of ERG abnormalities have been reported in ONH. Subnormal b-wave amplitude is reported in up to one-third of eyes and, in a few cases, $\mathrm{ONH}$ has been associated with absent scotopic b-waves, suggesting retinal dysfunction similar to that in congenital stationary night blindness. ${ }^{20,21}$ Severe ERG abnormalities have been reported occasionally in eyes with microphthalmos, colobomata, or other defects..$^{20,21,32}$ In contrast, a few cases of $\mathrm{ONH}$ with supranormal b-wave amplitudes have been reported for the scotopic ERG ${ }^{19}$ or the photopic ERG. ${ }^{35}$ These could be explained by selective dysfunction involving the depolarizing bipolar cells, or by disinhibition of retinal function in the absence of ganglion cell-mediated feedback. ${ }^{17,19,36}$

The photopic flash ERG recorded in the present series was a non-standard, which limits interpretation to comparisons within the subject group. ${ }^{37}$ The posterior pole was illuminated evenly by the flashing screen, but the remaining retina was illuminated unevenly with

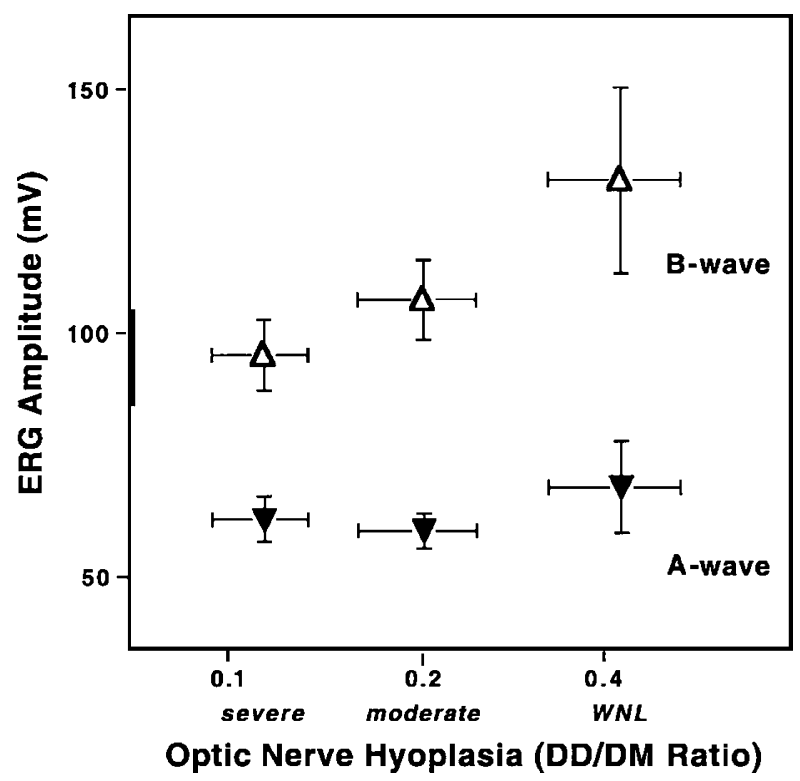

Figure 4 Mean values are shown for the a-wave and b-wave amplitudes for eyes classified as severe and moderate $\mathrm{ONH}$ and for fellow eyes (DD/DM $\leq 0.15, \leq 0.3$, and $\geq 0.3$, respectively). B-wave amplitude increases with $\mathrm{DD} / \mathrm{DM}$ category $(P<0.01)$ but there is no significant association with a-wave amplitude $(P>0.1)$. Bars indicate standard errors.
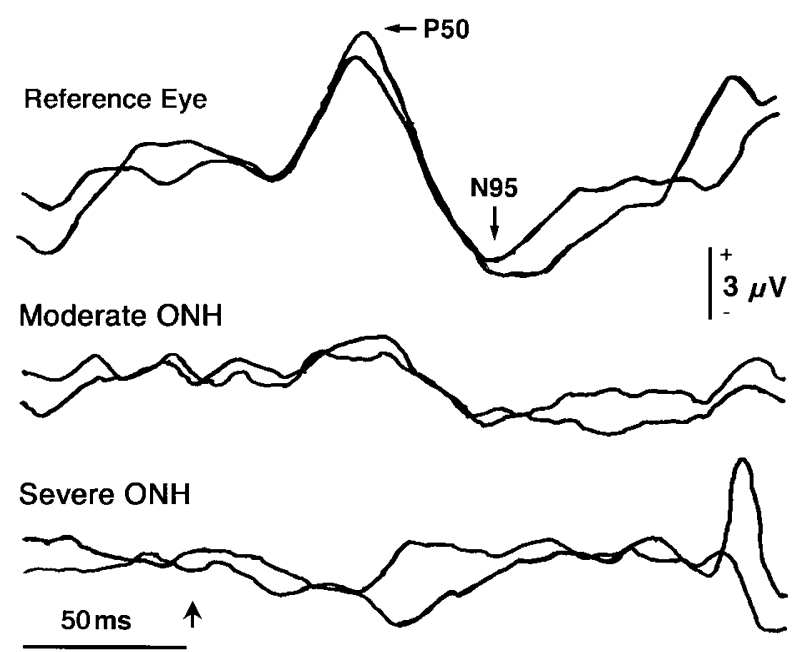

Figure 5 Typical pattern ERGs with chloral hydrate sedation to a $4^{\circ}$ alternating checkerboard are illustrated for eyes with severe and moderate $\mathrm{ONH}$ and for a fellow eye. Pattern ERG amplitude is associated with the severity of $\mathrm{ONH}$; however, there were large inter-individual variations. Arrow indicates pattern reversal.

scattered light. The stimulus was below the luminance level for the standard photopic ERG, which is already well below the saturation level for the a-wave. For the photopic b-wave, the luminance response function, or photopic hill, is complex owing to interactions between the hyperpolarizing and depolarizing bipolar cells of the 
retina. ${ }^{24}$ In healthy eyes, the flash used in the present study would elicit b-wave amplitudes in the rising phase of this function, where both depolarizing and hyperpolarizing bipolar cells add to the b-wave amplitude. Thus, the association of smaller b-waves with more severe $\mathrm{ONH}$ supports the contention that one or both populations of bipolar cells may be involved, but does not isolate specific deficits. Our ongoing studies of the luminance-response function of the full-field photopic ERG will investigate the photopic b-wave more thoroughly.

In alert healthy infants, pattern ERGs can be recorded using a skin electrode on the lower eyelid. ${ }^{38,39}$ However, cooperation and good fixation during many stimulus

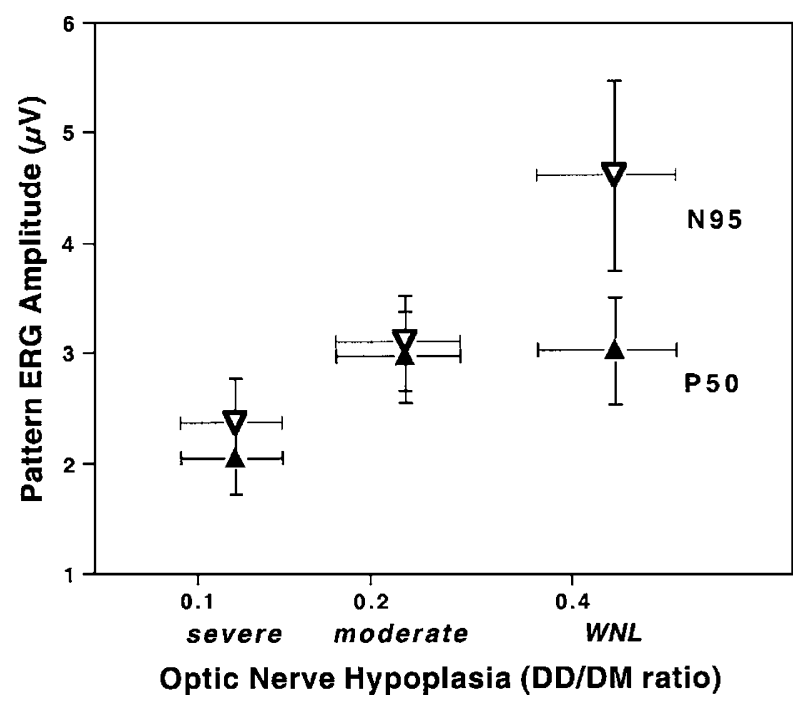

Figure 6 Mean values are shown for the pattern ERG P50 and $\mathrm{N} 95$ amplitudes for severe $\mathrm{ONH}$, moderate $\mathrm{ONH}$, and for fellow eyes based on the DD/DM classification $(\leq 0.15, \leq 0.3$, and $\geq 0.3$, respectively). Both P50 and N95 amplitude are significantly associated with the DD/DM category $(P<0.05$ and $P<0.02$, respectively). Bars indicate standard errors. presentations is required so the clinical utility of this strategy is limited. ${ }^{17}$ Pattern ERG recording without sedation would be unreliable or impossible in subjects with visual impairment and nystagmus. The present study demonstrates a strategy for recording pattern ERGs under sedation in infants and young children with an appropriate optical system. As the procedure requires sedation, we have relied on reference eyes (those with $\mathrm{DD} / \mathrm{DM}$ ratios within the range associated with normal vision) for comparisons. Clearly, these eyes are not a normal control group; some eyes show definite signs associated with mild ONH. However, the fact that ERGs to large checks were recorded in all 13 of the reference eyes in this series supports the validity of the technique. Technical difficulties, for example, inaccurate refraction or a poorly centred stimulus, could contribute to diminished amplitudes, but poor technique would not completely extinguish ERGs to these large checks. ${ }^{40}$ We contend that those infants with $\mathrm{ONH}$ and undetectable pattern ERGs have severe dysfunction of both the ganglion cells and of the more distal retinal cells.

Overall, the present study demonstrates that the congenital deficiency of ganglion cells in $\mathrm{ONH}$ produces the expected effects on the ERG to large checks. Specifically, the N95 is more affected than the P50 and the abnormalities are associated with the severity of the ONH. Pharmacological blockade of ganglion cells and spiking amacrine cells of the inner retina abolished most of the N95 and produced an earlier, diminished P50, indicating a more distal contribution to the P50. ${ }^{24}$ Similarly, when ganglion cell death is associated with optic atrophy, the N95 is severely diminished and the P50 is moderately diminished and earlier. ${ }^{26-28,41-43}$

The optimal check size for recording pattern ERGs in adults is between 0.75 and $1.0^{\circ}$, and the available data suggest that larger checks would be optimal for infants. ${ }^{38}$ For large field sizes, there is very little attenuation of either P50 or N95 amplitude for large check stimuli, ${ }^{28,44,45}$

Table 2 ERGs and tortuous retinal vessels in $\mathrm{ONH}$

\begin{tabular}{|c|c|c|c|}
\hline & $\begin{array}{c}\text { Tortuous veins and arteries } \\
\quad(\text { no. of eyes }=15)\end{array}$ & $\begin{array}{l}\text { Tortuous veins only } \\
\quad \text { (no. of eyes }=15)\end{array}$ & $\begin{array}{l}\text { Clinically normal vessels } \\
\quad \text { (no. of eyes }=59)\end{array}$ \\
\hline \multicolumn{4}{|l|}{ Large check $E R G^{\mathrm{a}}$} \\
\hline Undetectable/nil & $8(53 \%)$ & $3(20 \%)$ & $13(22 \%)$ \\
\hline Small $(<3.5 \mu \mathrm{V})$ & $6(40 \%)$ & $8(53 \%)$ & $20(34 \%)$ \\
\hline Large $(>3.5 \mu \mathrm{V})$ & $1(7 \%)$ & $4(27 \%)$ & $26(44 \%)$ \\
\hline \multicolumn{4}{|l|}{ Amplitudes $^{\mathrm{b}}$} \\
\hline P50 median (range) & Nil $(0-5.1 \mu \mathrm{V})$ & $3.1 \mu \mathrm{V}(0-7.2)$ & $2.2 \mu \mathrm{V}(0-9.9)$ \\
\hline N95 median (range) & Nil $(0-4.2 \mu \mathrm{V})$ & $3.3 \mu \mathrm{V}(0-5.3)$ & $3.2 \mu \mathrm{V}(0-7.0)$ \\
\hline $\mathrm{P} 50 / \mathrm{N} 95$ ratio & $1.5(0.2-6.3)$ & $1.1(0.5-1.9)$ & $0.8(0.2-5.2)$ \\
\hline
\end{tabular}

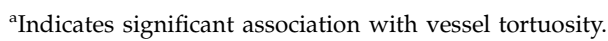

${ }^{\mathrm{b}}$ All eyes of all ONH severities are included for amplitudes. Only detectable signals are repotted for the P50/N95 ratio. 
but there is an increasing proportion of the response, which can be accounted for by local luminance modulation akin to the focal ERG. ${ }^{46}$ For the present $4{ }^{\circ}$ checks, a pattern-specific component is expected but this will derive primarily from stimulation of the outer part of our stimulus field, between 12 and $25^{\circ}$ from the fovea. ${ }^{46}$

Although that diminished or extinguished pattern ERGs are common in $\mathrm{ONH}$, within this cohort there is substantial heterogeneity. In clinically similar cases of $\mathrm{ONH}$, the ERG to large checks ranges from a completely undetectable response to a large-amplitude signal with well-preserved P50 and N95 components. Such heterogeneity suggests that there may be substantial variations in the cellular deficits associated with $\mathrm{ONH}$ and, quite likely, different aetiological processes.

There are many possible processes that could cause ganglion cell deficiency. ONH could arise from some initial failure of sufficient cellular differentiation.

However, the pathfinding processes for ganglion cells in the retina, optic nerve head and optic chiasm and formation of the retinotopic connections in the brainstem is complex. ${ }^{47-49}$ Deficiency in any one of these processes could lead to failure of accurate functional connections and excessive apoptosis in the ganglion cell layer. The relationships between the quantity and function of ganglion cells and the development of the more distal retinal cells are poorly understood. Differences in the timing of the ganglion cell loss could, however, be associated with the functional differences we observe among clinically similar cases of $\mathrm{ONH}$. It is interesting that the present study shows no association between the b-wave and the P50 amplitudes in the same eyes.

The presence of tortuous vessels has led to the theory that the primary lesion in $\mathrm{ONH}$ may be vascular. ${ }^{50,51}$ In the present study, we report a clear association between vascular tortuosity and retinal dyfunction, as indicated by absent pattern ERGs. This supports a link between vascular morphology and retinal dysfunction in a subset of our cases. Two hypotheses regarding the mechanism for retinal dysfunction in $\mathrm{ONH}$ remain viable: retinal dysgenesis may be a primary lesion leading to failure of ganglion cell development, or a primary deficit of ganglion cell development may be associated with retrograde retinal degeneration.

The present series has demonstrated associations between $\mathrm{ONH}$ and retinal electrophysiology. Specifically, normal photopic a-waves are evidence that the photoreceptor layer is functional in all of our cases. The mixed results for tests of inner nuclear layer and ganglion cell layer functions suggest that retinal dysfunction is a variable feature of $\mathrm{ONH}$. The strong association between pattern ERG abnormality and tortuous retinal vessels suggests that this vascular sign may be an indicator of retinal dysfunction distal to the ganglion cells.

\section{Acknowledgements}

This research was supported in part by The One Small Voice Foundation, the NIH NCRR GCRC Grant M01 RR-43, and was performed at the GCRC at Childrens Hospital Los Angeles. Travel costs were supported by the Carnegie Trust for the Universities of Scotland. We thank Wendy McNamara, Angela Groundland, and Caroline Chaplin for assistance with data and manuscript preparation.

\section{References}

1 Hotchkiss ML, Green WR. Optic nerve aplasia and hypoplasia. J Pediatr Ophthalmol Strabismus 1979; 16: 225-240.

2 DeMosier G. Median cranioencephalic dysraphias and olfacto-genital dysplasia. World Neurol 1962; 3: 485-503.

3 Hoyt CS. Optic nerve hypoplasia, changing perspective. Aust NZ J Ophthalmol 1986; 14: 325-331.

4 Zeki SM, Dutton GN. Mini review: optic nerve hypoplasia in children. Br J Ophthalmol 1990; 74: 300-304.

5 Skarf B, Hoyt CS. Optic nerve hypoplasia in children. Association with anomalies of the endocrine and CNS. Arch Ophthalmol 1984; 102: 62-67.

6 Lambert SR, Hoyt CS, Narahara MH. Optic nerve hypoplasia. Surv Ophthalmol 1987; 32: 1-9.

7 Borchert M, McCulloch DL, Rother C, Stout AU. Clinical assessment, optic disk measurements and visual-evoked potential in optic-nerve hypoplasia. Am J Ophthalmol 1995; 120: 605-612.

8 Hoyt CS, Good WV. Do we really know the difference between optic nerve hypoplasia and atrophy? Eye 1992; 6: 201-204.

9 Zeki SM, Dudgeon J, Dutton GN. Reappraisal of the ratio of disc to macula/disc diameter in optic nerve hypoplasia. $\mathrm{Br} \mathrm{J}$ Ophthalmol 1991; 75: 538-541.

10 Borchert MS, McCulloch DL. Clinical value of VEP and disc size in optic nerve hypoplasia. Invest Ophthalmol Vis Sci 1992; 33(Suppl 4): 225.

11 Waugh MC, Chong WK, Sonksen P. Neuroimaging in children with congenital disorders of the peripheral visual system. Dev Med Child Neurol 1998; 40: 812-819.

12 Hellstrom A, Wiklund LM, Svensson E. Diagnostic value of magnetic resonance imaging and planimetric measurement of optic disc size in confirming optic nerve hypoplasia. J AAPOS 1999; 3: 104-108.

13 Barr DB, Weir CR, Purdie AT. An appraisal of the discmacula distance to disc diameter ratio in the assessment of optic disc size. Ophthal Physiol Opt 1999; 19: 365-375.

14 Weiss AH, Kelly JP. Acuity, ophthalmoscopy and visually evoked potentials in the prediction of visual outcome in infants with bilateral optic nerve hypoplasia. J AAPOS 2003; 7: 108-115.

15 Alvarez E, Wakakura M, Khan Z, Dutton GN. The discmacula to disc diameter ratio: a new test for confirming optic nerve hypoplasia in children. J Pediatr Ophthalmol Strab 1988; 25: 151-154. 
16 Ouvrier RA, Billson F. Optic-nerve hypoplasia - a review. J Child Neurol 1986; 1: 181-188.

17 Kriss A, Russell-Eggitt I. Electrophysiological assessment of visual pathway function in infants. Eye 1992; 6: 145-153.

18 Borchert MS, Van Boemel GB, McCulloch DL. Correlation of VEP and ERG with visual outcome in infants with optic nerve hypoplasia. Invest Ophthalmol Vis Sci 2000; 41: 1274.

19 Sprague JB, Wilson WB. Electrophysiologic findings in bilateral optic nerve hypoplasia. Arch Ophthalmol 1981; 99: 1028-1029.

20 Cibis GW, Fitzgerald KM. Optic nerve hypoplasia in association with brain anomalies and an abnormal electroretinogram. Doc Ophthalmol 1994; 86: 11-22.

21 Janáky M, Deak A, Pelle Z, Benedek G. Electrophysiological alterations in patients with optic nerve hypoplasia. Doc Ophthalmol 1994; 86: 247-257.

22 Rangaswamy NV, Frishman LJ, Dorotheo EU, Schiffman JS, Bahrani HM, Tang RA. Photopic ERGs in patients with optic neuropathies: comparison with primate ERGs after pharmacologic blockade of inner retina. Invest Ophthalmol Vis Sci 2004; 45: 3827-3837.

23 Viswanathan S, Frishman L, Robson JG. The uniform field and pattern ERG in macaques with experimental glaucoma: removal of spiking activity. Invest Ophthalmol Vis Sci 2000; 41: 2797-2810.

24 Uneo S, Kondo M, Niwa Y, Terasaki H, Miyaki Y. Luminance dependence of neural components that underlies the primate photopic electroretinogram. Invest Ophthalmol Vis Sci 2004; 45: 1033-1040.

25 Holder GE, Votruba M, Cazrter AC, Bhattacharya SS, Fitzke FW, Moore AT. Electrophysiological findings in dominant optic atrophy (DOA) linking the OPA1 locus on chromosome 3q 28-qter. Doc Ophthalmol 1999; 95: 217-288.

26 Harrison JM, O'Connor PS, Young RSL, Kincaid M, Bentley $R$. The pattern ERG in man following resection of the optic nerve. Invest Ophthalmol Vis Sci 1987; 28: 492-499.

27 Holder GE. Pattern electroretinography (PERG) in an integrated approach to visual pathway diagnosis. Prog Retinal Eye Res 2001; 20: 531-561.

28 Bach M. Electrophysiological approaches for early detection of glaucoma. Eur J Ophthalmol 2001; 11(Suppl 2): S41-S49.

29 Dawson WW, Trick GL, Litzkow CA. Improved electrode for electroretinography. Invest Ophthalmol Vis Sci 1989; 18: 988-991.

30 Hawlina M, Konec B. New non-corneal 'HK-loop' electrode for clinical ERG. Doc Ophthalmol 1992; 81: 253-259.

31 McCulloch DL, van Boemel GB, Borchert MS. Comparison of corneal, conjunctival and skin electrodes for pattern electroretinograms. Doc Ophthalmol 1998; 94: 327-340.

32 Margolith D, Jan JE, McCormick AQ, Tze WJ, Lapointe J. Clinical spectrum of optic nerve hypoplasia. Review of 51 patients. Dev Med Child Neurol 1984; 71: 427-433.

33 Siatkowski RM, Sanchez JC, Andrade R, Alvarez A. The clinical, neuroradiographic, and endocrinologic profile of patients with bilateral optic nerve hypoplasia. Ophthalmology 1997; 104: 493-496.
34 Francoise J, DeRouck A. Electroretinographical study of the hypoplasia of the optic nerve. Ophthalmologica 1976; 172 308-330.

35 Kriss A, Lloyd C, Taylor D. Flash ERG and VEP findings in young patients with optic nerve hypoplasia. Int Soc Clin Electrophys Vision XXX Symposium, Vienna, May 1992

36 Zucker CL, Dowling JE. Centrifugal fibers synapse on dopaminergic interplexiform cells in the teleost retina. Nature 1987; 330: 166-168.

37 Marmor MF, Holder GE, Seeliger MW, Yamamoto S. Standard for clinical electroretinography (2004 update). Doc Ophthalmol 2004; 108: 107-114.

38 Fiorentini A, Pirchio M, Sandini G. Development of retinal acuity in infants evaluated with pattern electroretinography. Hum Neurobiol 1984; 3: 93-95.

39 Fiorentini A, Trimarchi C. Development of temporal properties of pattern electroretinogram and visual evoked potentials in infants. Vis Res 1992; 32: 1609-1621.

40 Bach M, Mathieu M. Different effect of dioptric defocus vs light scatter on the pattern electroretinogram (PERG). Doc Ophthalmol 2004; 108: 99-106.

41 Mashima Y, Oguchi Y. Clinical study of the pattern electroretinogram in patients with optic nerve damage. Doc Ophthalmol 1985; 61: 91-96.

42 Nesher R, Trick GL. The pattern electroretinogram in retinal and optic nerve disease. Doc Ophthalmol 1991; 77: 225-235.

43 Bach M, Gerling J, Geiger K. Optic atrophy reduces the pattern electroretinogram for both fine and coarse stimulus patterns. Clin Vis Sci 1992; 7: 327-333.

44 Török B, Meyer M, Wildberger $\mathrm{H}$. The influence of pattern size on amplitude, latency and wave form of retinal and cortical potentials elicited by checkerboard pattern reversal and stimulus onset-offset. Electroenceph Clin Neurophysiol 1992; 84: 13-19.

45 Bach M, Holder GE. Check size tuning of the pattern electroretinogram: a reappraisal. Doc Ophthalmol 1996; 92: 193-202.

46 Thompson DA, Drasdo N. The origins of luminance and pattern responses of the pattern electroretinogram. Int J Psychophysiol 1994; 16: 219-227.

47 Oster SF, Deiner M, Birgbauer E, Sretavan DW. Ganglion cell axon pathfinding in the retina and optic nerve. Sem Cell Dev Biol 2004; 15: 125-136.

48 Mann F, Harris WA, Hold CE. New views on retinal axon development: a navigational guide. Int J Dev Biol 2004; 48: 957-964.

49 Stuermer C, Bastmeyer M. The retinal axon's pathfinding to the optic disk. Prog Neurobiol 2000; 62: 197-214.

50 Lubinsky MS. Hypothesis: septo-optic dysplasia is a vascular disruption sequence. Am J Med Genet 1997; 69: 235-236.

51 Hellstrom A, Wiklund LM, Svensson E, Albertsson-Wikland $\mathrm{K}$, Stromland K. Optic nerve hypoplasia with isolated tortuosity of the retinal veins - A marker of endocrinopathy. Arch Ophthalmol 1999; 117: 880-884. 